\title{
BASIN EFFECTS AND LIMITATIONS OF 1D SITE RESPONSE ANALYSIS FROM 2D NUMERICAL MODELS OF THE THORNDON BASIN
}

\author{
Christopher R. McGann', Brendon A. Bradley², \\ Liam M. Wotherspoon ${ }^{3}$ and Robin L. Lee ${ }^{4}$
}

(Submitted February 2020; Reviewed June 2020; Accepted August 2020)

\begin{abstract}
Plane strain (2D) finite element models are used to examine factors contributing to basin effects observed for multiple seismic events at sites in the Thorndon basin of Wellington, New Zealand. The models consider linear elastic soil and rock response when subjected to vertically-propagating shear waves. Depth-dependent shear wave velocities are considered in the soil layers, and the effects of random variations of soil velocity within layers are modelled. Various rock shear wave velocity configurations are considered to evaluate their effect on the modelled surficial response. It is shown that these simple 2D models are able to capture basin reverberations and compare more favourably to observations from strong motion recordings than conventional 1D site response models. It is also shown that consideration of a horizontal impedance contrast across the Wellington Fault affects spectral response and amplification at longer periods, suggesting the importance of this feature in future ground motion modelling studies in the Wellington region.
\end{abstract}

\section{INTRODUCTION}

Conventional analytical/numerical techniques used for seismic ground response analysis are largely based on 1D wave propagation assumptions, despite the growing body of evidence from vertical array sites in Japan and California [e.g. 1-4] which indicates that $1 \mathrm{D}$ analysis is only appropriate at a minority of sites. The limitations of this so-called "SH1D" analysis, which assumes infinite horizontal layers and vertically propagating horizontally polarised shear (SH) waves only, come from mechanisms related to how the site is modelled and defined. For example, wave scattering from small-scale soil heterogeneity cannot be captured and 2D/3D geometry is not considered. Sedimentary basins and valleys laterally confined by rock have long been known to contribute to the amplification of seismic ground motions through several 2D and 3D mechanisms. These basin effects can be broadly separated into basin reverberation effects due to trapped wave energy, and basin-edge effects due to resonance and constructive interference of basin-generated surface waves and vertically propagating SH-waves [e.g. 5-8].

The geology and geotechnical conditions in Wellington are complex and variable, with the surficial geology shifting from rock with various degrees of weathering in the surrounding hills to Pleistocene deposits, Holocene sediments, and reclaimed land near the waterfront [9]. In addition to significant local site effects, ground motions observed in past events in Wellington show clear evidence of basin effects [10-12]. These basin effects are particularly evident in the Thorndon basin in the 2016 Kaikōura earthquake, where spectral accelerations in the 1-2 second range exceeded the 500-year return-period design response spectrum. Numerical models of the Wellington region back up these empirical observations and demonstrate the utility of simulations for studying this problem, with the 3D ground motion simulations of Benites and Olsen [13] inferring similar response to previous events, and the 2D models of Adams et al. $[14,15]$ demonstrating the development of basin-edge effects in the Lower Hutt Valley.
In this paper, linear elastic plane strain (2D) wave propagation models are developed for a cross-section through the Thorndon basin to further examine mechanisms contributing to basin effects in central Wellington and compared to the results of conventional SH1D ground response models. The plane of the models crosses the Wellington Fault $[16,17]$, which has a near vertical dip and a strike direction nearly perpendicular to the model domain [18]. The fault bounds a steep-sided soil basin and also potentially forms a deeper lateral stiffness variation due to a possible horizontal stiffness/velocity contrast from the more intact, confined, and less weathered rock of the western footwall and the relatively more fractured (due to secondary faults), less confined, and more weathered rock on the hanging wall side $[17,19,20]$. This horizontal velocity contrast across the fault zone is considered within the simulations to assess its effect on the development of longer-period basin effects. .

\section{MODEL DEVELOPMENT}

Plane strain models of a vertical slice through the Thorndon basin are developed and analysed using the OpenSees finite element analysis platform [21]. All models use stabilised single integration point quadrilateral elements [22] to model the soil and rock domain. Only linear elastic constitutive response is considered, as the focus of this study is on wave propagation rather than the details of nonlinear soil response. All wave propagation occurs in the plane of the model domain.

The considered model domain is shown in Figure 1. This domain extends from the hills northwest of central Wellington, across the Wellington Fault, through the Thorndon basin and across Lambton Harbour, to the northwestern slopes of Mt Victoria near Oriental Bay. This domain is chosen as it allows for an investigation of the relative effects of the sedimentary soil basin and a potential deeper lateral stiffness variation formed by a velocity contrast across the Wellington Fault zone due to secondary faulting on the hanging wall side of the fault $[17,19,20]$, and links in with other ongoing research.

\footnotetext{
1 Corresponding Author, Senior Lecturer, University of Canterbury, Christchurch, christopher.mcgann@canterbury.ac.nz (Member)

2 Professor, University of Canterbury, Christchurch, brendon.bradley@canterbury.ac.nz (Member)

3 Associate Professor, The University of Auckland, Auckland, l.wotherspoon@auckland.ac.nz (Fellow)

4 Lecturer, University of Canterbury, Christchurch, robin.lee@canterbury.ac.nz (Member)
} 


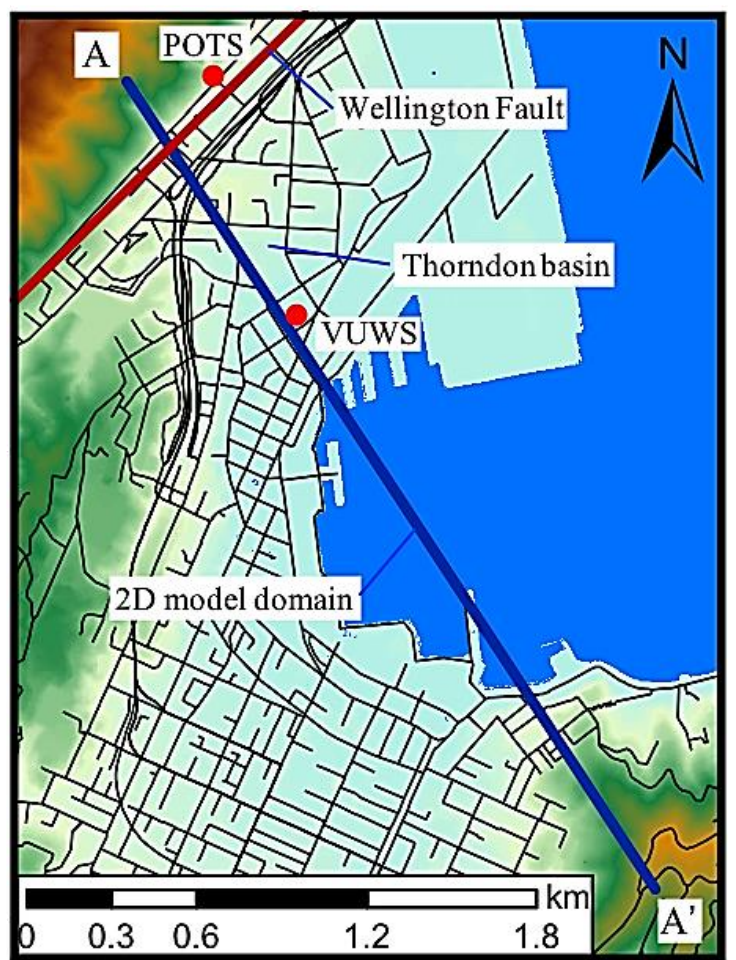

Figure 1: Location and orientation of the 2D model domain. Wellington Fault and key SMS indicated for reference.

The geometry of the basin model is developed based on digital elevation data, to form the surface of the mesh, and the depthto-bedrock contour map of Semmens et al. [9] to establish the bounds of the soil basin. Bathymetry data are used in offshore regions of the domain where the Semmens et al. [9] bedrock model is poorly constrained by data. Two model configurations are considered in order to gauge the effects of various modeling decisions and basin definitions. These configurations are shown in Figure 2, and are referred to in all subsequent discussion as the base mesh and the fault mesh as labelled. For reference, the model domain is approximately $3.25 \mathrm{~km}$ wide and has a maximum height of $430 \mathrm{~m}$. The element size varies throughout the mesh with a smooth transition from an average element size of 2-4 m near the ground surface to an average size of $15 \mathrm{~m}$ at greater depths. These element sizes limit the frequency content that can be transmitted through the mesh, however, the chosen level of mesh refinement represents a practical compromise between frequency content and computational efficiency as analyses with a consistently-refined mesh did not change the major conclusions drawn from the less-refined models. The reference site noted in Figure 2 is the location of the VUWS strong motion station. Unless explicitly noted, all subsequent analysis and discussion refers to the empirical observations and corresponding simulation results at this site.

\section{Soil Modelling and Properties}

The soil shear wave velocity $\left(V_{s}\right)$ distribution is based on the results of surface wave testing and analysis [23] near the reference site, cone penetration test (CPT) and standard penetration test (SPT) data obtained from the New Zealand Geotechnical Database [24], and the range of values suggested for the various regional geologic units by Semmens et al. [9]. Based on this data, the soil domain is roughly divided into two layers, a layer of softer soils near the ground surface and a deeper layer of more dense and stiff soils (layers Soil 1 and 2 in Figure 2, respectively). Simple depth-dependent power law functions are assumed in these layers such that

$V_{S}(z)=160 z^{0.25}$
$V_{S}(z)=190 z^{0.25}$

in the soft and stiff layers, respectively. In both layers, $z$ is depth in metres and $V_{S}$ is in $\mathrm{m} / \mathrm{s}$. Figure 3(a) shows the resulting distribution of $V_{S}$ within these two soil layers. Both soil layers are assigned a Poisson's ratio of 0.3 and the mass densities of layers Soil 1 and 2 are taken as 1.7 and $1.8 \mathrm{Mg} / \mathrm{m}^{3}$, respectively. Mass and stiffness proportional Rayleigh damping is applied such that the damping ratio is $5 \%$ at 0.2 and $20 \mathrm{~Hz}$ in all layers. No numerical damping is considered. Additional analyses with lower damping ratios indicate that the primary results of the models are not sensitive to the assigned damping ratio and conclusions drawn from the 5\% damping ratio cases are applicable across other appropriate levels of Rayleigh damping.

\section{Random Field Models for Soil Layers}

The effects of spatial variability in the near-surface soils are also examined by generating spatially-varying random fields for the shear wave velocities within the soft and stiff soil layers. These random fields are computed using an exponential model and the randomization method [e.g., 25]. The simple depthdependent $V_{s}$ profile of Figure 3(a) is taken as the mean value for each soil element and a standard deviation of the natural logarithm of $V_{S}$ is assumed to be 0.2 throughout the soil domain. The horizontal autocorrelation length is set as $80 \mathrm{~m}$ and $100 \mathrm{~m}$ in layers Soil 1 and 2, respectively. Two isotropy conditions are considered, a fully isotropic condition where the vertical and horizontal autocorrelation lengths are the same, and an anisotropic condition where the vertical autocorrelation length is one tenth of the horizontal, i.e. the vertical autocorrelation length is $8 \mathrm{~m}$ in the soft soil and $10 \mathrm{~m}$ in the stiff soil. Ten realizations of the random velocity fields are analysed for both isotropy conditions. Figures 3(b) and (c) show example anisotropic random fields, highlighting the variability of the velocities relative to the mean condition.

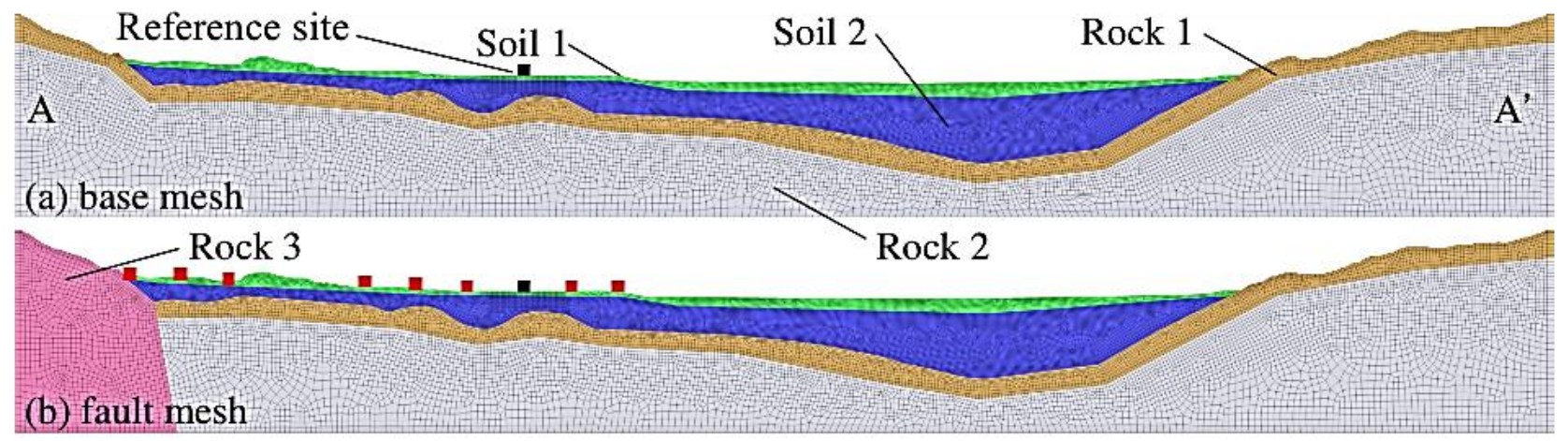

Figure 2: Computational mesh for $2 D$ models. (a) Base mesh: soil basin only, no consideration for the Wellington Fault zone; (b) Fault mesh: horizontal impedance across the Wellington Fault zone. Red dots indicate basin effect analysis locations. 


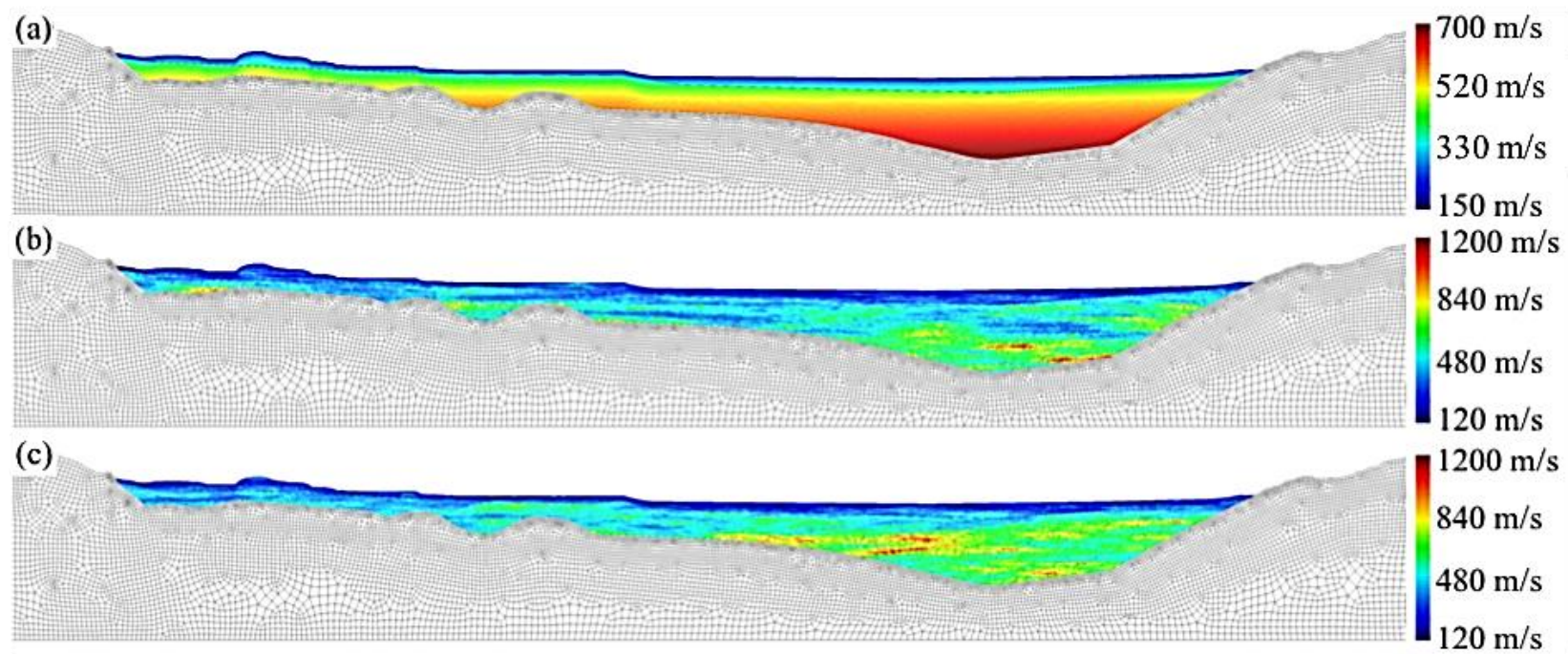

Figure 3: Shear wave velocity profile for soil layers in basin model. (a) Baseline depth-dependent shear wave velocity distribution; (b) and (c) Random anisotropic shear wave velocity realisations. Note that magnitude scales are different in (a) vs (b) and (c).

\section{Rock Modelling and Properties}

Several rock velocity structures are considered for each of the two model configurations in order to explore their impact on the basin effects observed in the 2D models. The five distinct cases are summarised in Table 1. All cases consider the same soil properties, only the rock velocities are varied. The rock $V_{S}$ values are assumed based on the guidance of Semmens et al. [9]. Mass densities for all rock layers are taken as $2.6 \mathrm{Mg} / \mathrm{m}^{3}$ after [26] and Poisson's ratio is assumed to be 0.3 in all rock layers. Random fields are not considered in the rock layers in the current study. The base mesh of Figure 2(a) considers only a soil basin underlain by rock and makes no consideration for any horizontal impedance contrast within the rock layers due to secondary faulting. As shown in Table 1, two rock velocity structures are considered for the base mesh: case B1 where a band of $800 \mathrm{~m} / \mathrm{s}$ weathered rock is underlain by a very stiff rock with $V_{s}=2000 \mathrm{~m} / \mathrm{s}$ and case B2 where the weathered rock is underlain by a rock layer with $V_{S}=1000 \mathrm{~m} / \mathrm{s}$.

Table 1: Rock velocity structures considered for the two model configurations of Figure 2.

\begin{tabular}{lcccc}
$\begin{array}{l}\text { Model } \\
\text { Configuration }\end{array}$ & $\begin{array}{c}\text { Case } \\
\text { ID }\end{array}$ & $\begin{array}{c}\text { Rock 1 } \\
\mathbf{V}_{\mathbf{s}}(\mathbf{m} / \mathbf{s})\end{array}$ & $\begin{array}{c}\text { Rock 2 } \\
\mathbf{V}_{\mathbf{s}}(\mathbf{m} / \mathbf{s})\end{array}$ & $\begin{array}{c}\text { Rock 3 } \\
\mathbf{V}_{\mathbf{s}}(\mathbf{m} / \mathbf{s})\end{array}$ \\
\hline Base mesh & B1 & 800 & 2000 & - \\
& B2 & 800 & 1000 & - \\
\hline Fault mesh & F1 & 800 & 1250 & 2000 \\
& F2 & 800 & 1000 & 2000 \\
& F3 & 800 & 1500 & 2000 \\
\hline
\end{tabular}

The fault mesh configuration of Figure 2(b) makes simplified consideration for a horizontal impedance contrast across the Wellington Fault zone, which as shown in Figure 1 passes through the model domain nearly perpendicular to the considered plane. The location of the fault is clearly visible in Figure 2(b) as the boundary between layers Rock 2 and 3. A dip angle of $80^{\circ}$ is assigned to the fault after Litchfield et al. [18]. Three rock velocity structures are considered for the fault mesh in which the shear wave velocity of layer Rock 2 (see Fig. 2) is varied as noted in Table 1 for cases F1, F2, and F3. The crossfault velocity contrast in the fault mesh models is motivated by the presence of second-order faults that bifurcate off of the main Wellington Fault on the hanging wall side [17, 19], as it is likely that the rock on the hanging wall side is relatively more crushed and cracked, resulting is a lower stiffness than the more intact rock on the footwall side. Additionally, the rake angle for the Wellington Fault is estimated at $15^{\circ}[18]$, indicating that a slight degree of normal fault movement may have occurred in previous ruptures, further contributing to a larger stiffness on the footwall side.

\section{Boundary and Loading Conditions}

Five ground motions recorded at the POTS strong motion station (see Figure 1) are considered as input ground motions. The POTS station is sited on weathered rock and deconvolution of records recorded at this station provides the best available approximation for the ground motions within the bedrock below the basin. The horizontal components recorded at POTS are rotated to align with the model domain and the horizontal component in the plane of the model is applied as the input excitation. Vertical input excitation is not applied.

Table 2 summarises the in-plane component of the five considered ground motions, providing the moment magnitude, $M_{w}$, and the peak accelerations at the POTS station and the reference site, which is the VUWS strong motion station. These ground motions correspond to the largest magnitude events with the highest signal-to-noise ratio recorded during two separate time periods in 2013 and 2016. Ground motions A-D are part of the 2013 Cook Strait earthquake sequence - motion A is the 16 August 2013 Lake Grassmere earthquake [10] - and motion $\mathrm{E}$ is an aftershock of the Kaikoura earthquake from December 2016. While these motions represent the largest magnitude events in the desired time window, the amplitudes are small enough that the linear viscoelastic approach adopted in the models is reasonable for comparing simulations with observations at the reference site and elsewhere in the models.

The spatial variability of the incident motion is ignored and the deconvolved and rotated POTS motions are applied across the entire 2D model domain as in-plane vertically-incident SVwaves. The horizontal extents of the models are extended out past those shown in Figure 2 to minimise boundary effects, and periodic boundaries are enforced by tying the nodes at opposing sides together such that they have equal degrees-of-freedom. 
Table 2: Characteristic of considered ground motions.

\begin{tabular}{ccccc}
$\begin{array}{c}\text { Ground } \\
\text { motion ID }\end{array}$ & Year & $\mathbf{M}_{\mathbf{w}}$ & $\begin{array}{c}\text { POTS } \\
\text { PGA }\end{array}$ & $\begin{array}{c}\text { Reference } \\
\text { Site PGA (g) }\end{array}$ \\
\hline A & 2013 & 6.6 & 0.04 & 0.18 \\
B & 2013 & 5.5 & 0.007 & 0.038 \\
C & 2013 & 5.9 & 0.009 & 0.035 \\
D & 2013 & 5.5 & 0.002 & 0.014 \\
E & 2016 & 5.5 & 0.0025 & 0.01 \\
\hline
\end{tabular}

Ground motion excitation is applied to the models at the base using the compliant base method of Joyner and Chen [27] to account for an underlying elastic half-space with a mass density of $2.6 \mathrm{Mg} / \mathrm{m}^{3}$ and $V_{s}=2000 \mathrm{~m} / \mathrm{s}$. The adopted treatment of the boundaries and ground motion application, while greatly simplified, is useful and sufficient for the purposes of this study, given the focus on the relative $1 \mathrm{D} / 2 \mathrm{D}$ response and the observation that the response at longer periods is less affected by ignoring spatial variability in the incident motion.

\section{SH1D Site Response Models for Reference Site}

One-dimensional (SH1D) site response models are developed for the soil profile below the reference site for the purpose of comparison with the various $2 \mathrm{D}$ models. The SH1D models have identical mesh discretization, layer boundaries, and distributions of shear wave velocity and other elastic properties as a vertical line extending down through each $2 \mathrm{D}$ model configuration below the reference site. The SH1D models are developed and analysed in OpenSees [21] using a single column of quadrilateral elements with periodic boundary conditions and the same compliant base approach used in the 2D models. Comparisons between the SH1D and 2D models distinguish 1D and $2 \mathrm{D}$ wave propagation effects and allows for commentary on the relative strengths and weaknesses of each approach.

\section{EVALUATION OF RESULTS AT REFERENCE SITE}

Assessment of the 2D and 1D ground response models is made through comparison of simulated results with the observed surficial response at the reference site (VUWS station). Initial comparisons are made for a single input ground motion (Ground Motion A from Table 2) in order to highlight particular features of the model response and simplify discussion. Further assessments are made using all five ground motions listed in Table 2 to assess any systematic effects and to demonstrate the significant differences between the 2D and 1D models.

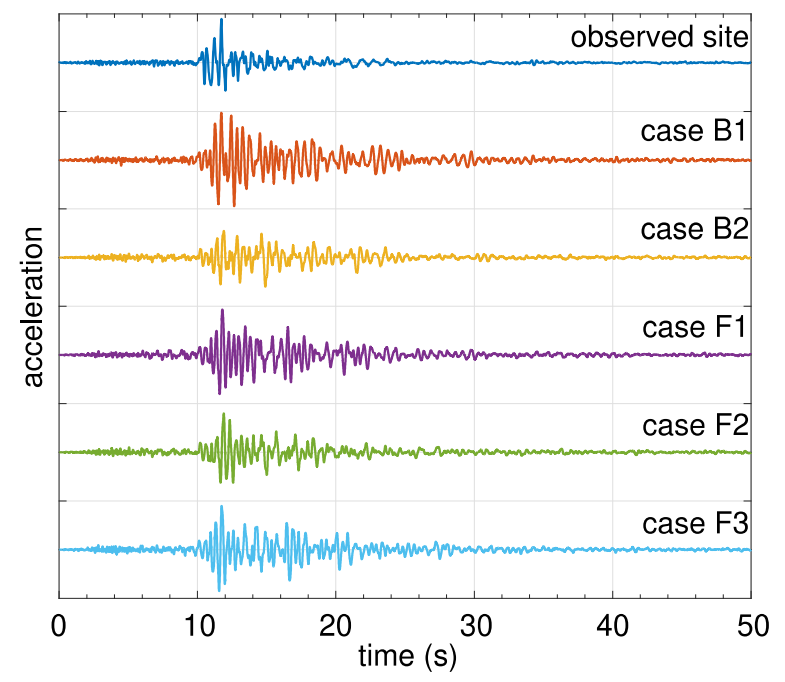

Figure 4: Horizontal acceleration time series for $2 D$ models with range of rock velocity structures at the reference site for Ground Motion A (Lake Grassmere event).
Figure 4 compares the horizontal acceleration time series at the reference site for the five 2D models with the observed acceleration response for Ground Motion A (Lake Grassmere earthquake). It is not expected that the models will match the observed surficial acceleration time series cycle-for-cycle due to uncertainty in the modelling of soil/rock layer boundaries, material properties, and the input ground motion, among other factors, but several useful observations can still be made. The key observation is that changes in the rock shear wave velocity structure of the models lead to variations in the simulated response. There is also a discernible difference between the base and fault mesh cases, particularly for cases F2 and F3 where much like the observed record, there is an abrupt decrease in amplitude after the initial high amplitude pulses rather than the more gradual amplitude decrease evident for cases B1 and B2.

\section{Acceleration Response Spectra for Lake Grassmere Event}

Though there are observable differences between the simulation cases in Figure 4, it is difficult to infer robust conclusions on the relative quality of the five different model cases based solely on the acceleration waveforms for a single ground motion. To further assess and compare the five considered basin model cases, Figure 5 compares the horizontal acceleration response spectra (5\% damped) from the 2D models for Ground Motion A to the corresponding acceleration response spectra for the observed surficial response at the reference and POTS sites. The surficial response spectra (also 5\% damped) from the SH1D models developed for the reference site are also shown in Figure 5. As previously discussed, the shear wave velocity profiles in these SH1D models correspond directly to the 1D velocity profile below the reference site in each $2 \mathrm{D}$ model, and due to the different rock shear wave velocity structures considered in the 2D models, these SH1D models differ for most, but not all, of the cases.

All of the 2D model results compare reasonably well to the observed response at the VUWS station, but clear differences are observed across the considered rock shear wave velocity structure cases. For the two base mesh simulations, case B2 compares better to observations across all periods, and particularly in the 1-3 second period range where basin effects are evident in the observed VUWS response spectrum. Case B1 does compare better to the observed response at higher frequencies, however, due to the limitations of the mesh size and the effects of the spatially invariable input motion approach has on higher frequencies, this similarity is likely due to chance rather than some particular physical aspect of this case. Out of the fault mesh simulations, case F2 has the best overall match with the observed response spectrum, and arguably the best overall match of all five cases.

It is of particular interest that cases B2 and F2 are the most similar to the observed response, as these two cases differ only in their treatment of the velocity contrast across the Wellington Fault zone, thus enabling a direct evaluation of the effect of this velocity contrast on the simulated results. In addition, because cases B2 and F2 have identical 1D soil profiles below the reference site, any $1 \mathrm{D}$ and $2 \mathrm{D}$ effects can be clearly separated. This means that any differences in the 2D model results across these cases can be attributed solely to differences in the 2D models. Based on the results shown in Figure 5, it appears that case F2 provides a better overall match with the observed response, particularly in the 1-3 second period range of interest for basin effects. This is suggestive that the velocity contrast across the Wellington Fault zone is a key feature of the response in the Thorndon basin, however, this observation is explored further using other ground motions in subsequent sections. 

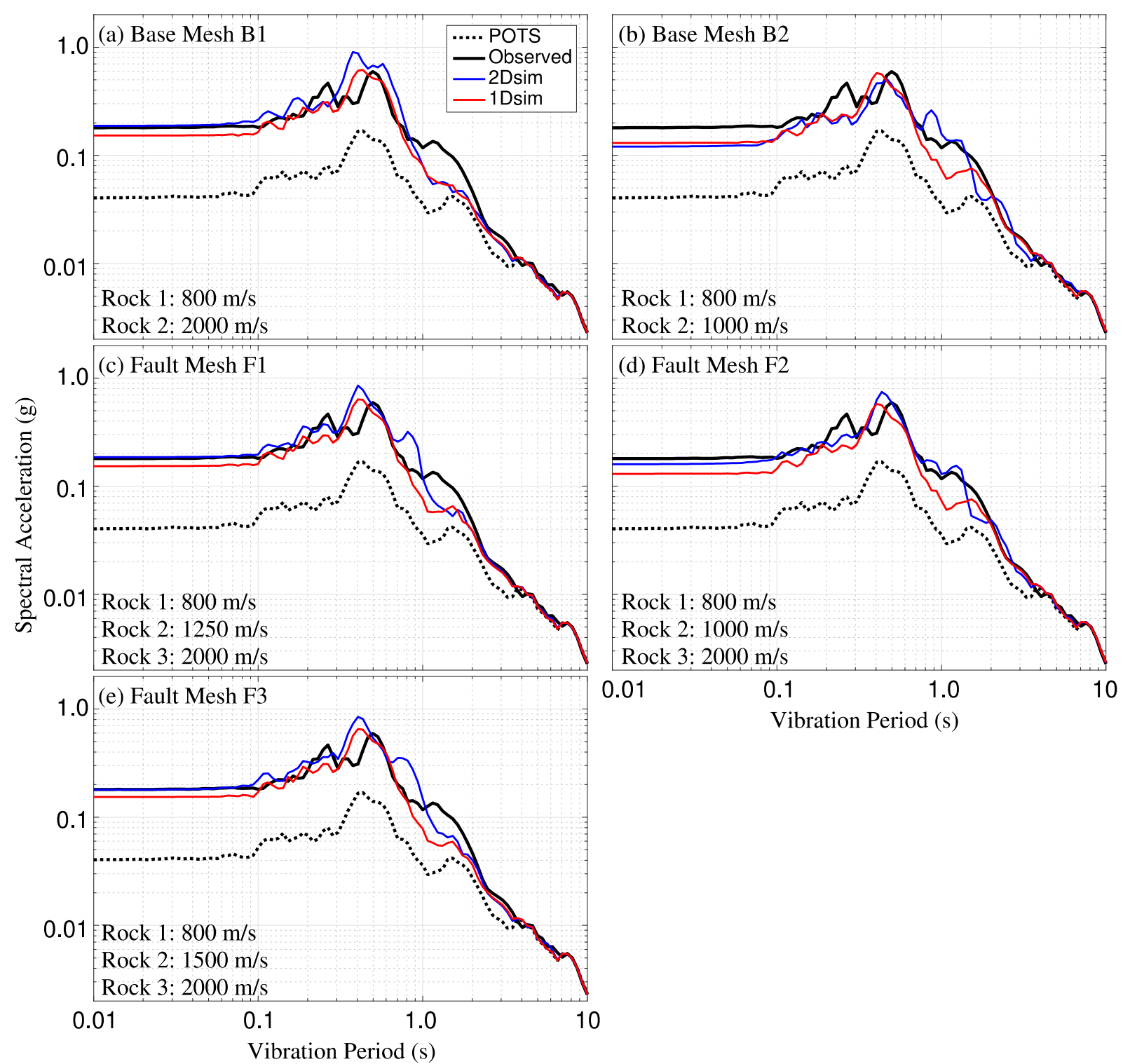

Vibration Period (s)

Figure 5: Horizontal acceleration response spectra for 2D and SH1D models compared to input motion (POTS) and the observed surficial acceleration at the reference site for Ground Motion A. (a) Case B1; (b) Case B2; (c) Case F1; (d) Case F2; (e) Case F3.

\section{Spectral Amplification and Limitations of SH1D Analysis}

Further comparison between the different 2D and SH1D models is made through the consideration of the spectral amplification at the reference site (both observed and simulated) for all five ground motions listed in Table 2. In this context, the spectral amplification is defined as the ratio of the surficial horizontal response spectra at the reference site to that observed at the POTS station for each motion. As previously discussed, POTS is a rock outcrop site, and it is assumed that the motions recorded here are representative of the motion that occurred at the soil-rock interface below the reference site. This is not strictly correct, but defining the amplification in this way for both the observations and simulations is appropriate for relative comparisons between the two.

The spectral amplifications computed in this manner for the observations and simulations are shown in Figure 6 for the various 2D model cases and Figure 7 for the corresponding SH1D models. The red lines indicate the mean simulation response across all five ground motions, while the grey lines indicate the results for each individual ground motion. The observed responses shown are the mean of the observed response in all five ground motions, and are the same in each of these figures. Note that the grey lines in Figures 6(f) and 7(f) correspond to the observations for each individual ground motion and correspond to simulated results in all remaining subfigures.

As shown in Figure 6, the different rock velocity structures all produce different results that correspond to the mean observed response in different ways, though none of the cases match all of the features of the observed amplification. Similar to the previous results for only Ground Motion A, the mean responses for Cases B2 and F2 appear to compare best overall to the observations, particularly in regard to amplification at periods greater than one second. It is also evident in Figures 6(a)-(e) that there is some variability in the $2 \mathrm{D}$ model response across the considered ground motions, and that this variability is somewhat less than that in the observed amplification shown in Figure 6(f), particularly in the middle period range from about $0.1-2$ seconds. This is expected as the 2D models consider only a series of homogeneous layers and likely do not represent the true complexity of the site or basin response nor can these models fully represent the variability in source and path effects that could lead to variable observed site response. The shortcomings of the 2D models related to homogeneity within the soil layers are explored further in subsequent sections. 


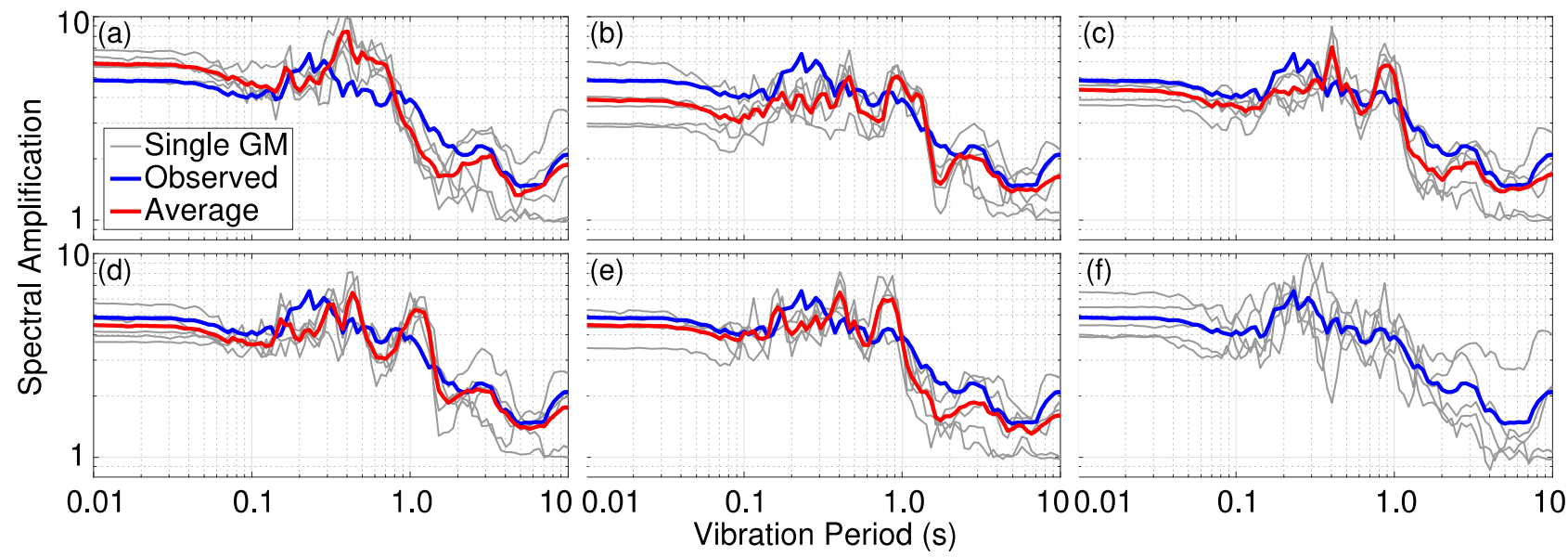

Figure 6: Spectral amplification of the reference site with respect to POTS in the 2D models for horizontal results of all considered ground motions. Grey lines show results for individual simulations, red lines show the mean across all simulations, and blue lines show the mean of the observed response. (a) Case B1; (b) Case B2; (c) Case F1; (d) Case F2; (e) Case F3; (f) Observed response.

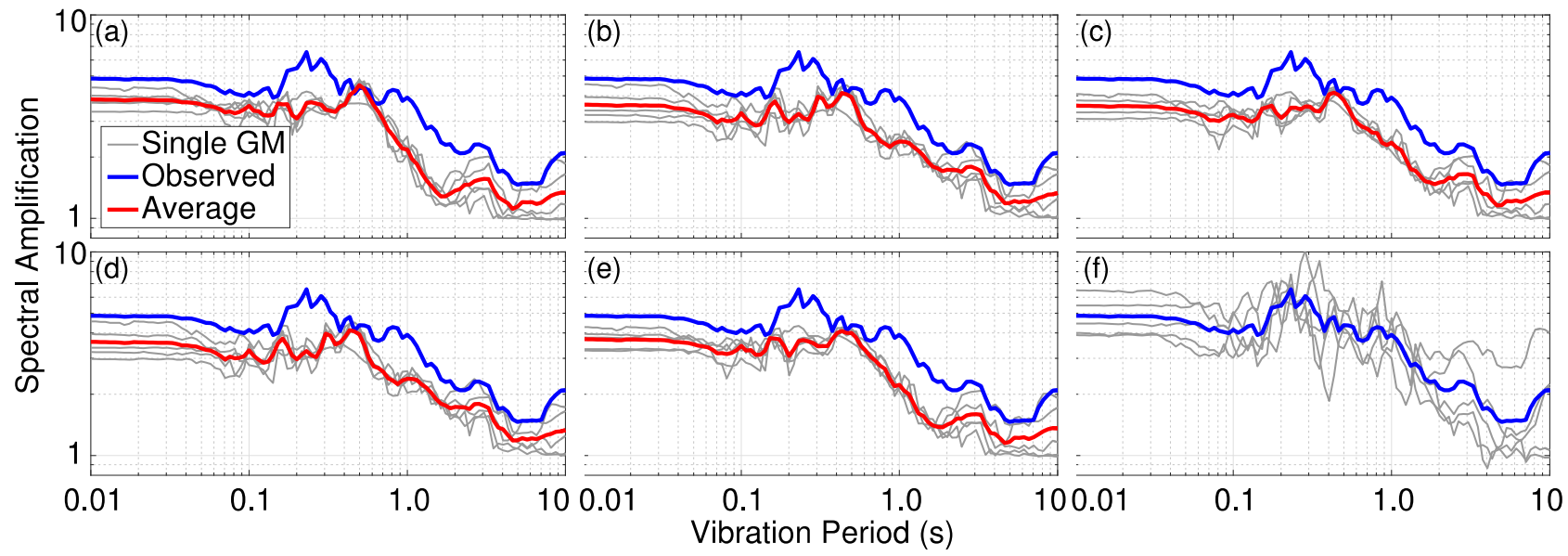

Figure 7: Spectral amplification of the reference site relative to POTS in the SH1D models for all considered ground motions. Grey lines show results for individual simulations, red lines show the mean across all simulations, and blue lines show the mean of the observed response. (a) Case B1; (b) Case B2; (c) Case F1; (d) Case F2; (e) Case F3; (f) Observed response.

The results of Figure 7 more systematically highlight some of the shortcomings of SH1D ground response analysis for the reference site that were first evident in Figure 5. As shown in Figure 7, the peak amplification in the SH1D models at periods of about $0.4-0.5$ seconds corresponds relatively well with the mean observations for the same period range, but the SH1D models generally underpredict the observed amplifications at all other periods. For comparison, the corresponding 2D model results of Figure 6 are better across all rock velocity structure cases. Of particular note is the underprediction in the SH1D models at periods greater than 1 second. While the SH1D models do amplify the input motion at long periods, this amplification is less than that observed. Adjustments to the SH1D model parameters could likely improve predictions at shorter periods without sacrificing the response at the fundamental site period, but similar adjustments could not improve the predictions at longer periods while maintaining appropriate amplification at the other period ranges.

The inability of these models to capture the amplification across all periods is one of the major shortcomings of SH1D analysis for basin sites or other locations where the assumptions of SH1D analysis break down. Another shortcoming is also evident in Figure 7, which shows that the variability in spectral amplification across the considered ground motions is far less than that in the observed or 2D model responses, particularly in the 0.2-1 second period range. This reduced variability is directly related to the SH1D assumption of infinitely extending horizontal homogenous layers, and even though the 2D models of Figure 6 don't make explicit consideration for within-layer variability, it is clear that the consideration for varying and nonhorizontal layer boundaries is able to recoup some of the observed motion-to-motion variability at the reference site. It is important to note that the use of linear elastic soil response in the current study reduces model variability across the different ground motions, however, the trends here are representative of the general improvements realised by $2 \mathrm{D}$ analysis relative to SH1D analysis for this Thorndon basin site.

\section{BASIN EFFECTS ACROSS THORNDON BASIN}

Results in previous sections have only considered the reference site located roughly $75 \%$ of the approximately $1 \mathrm{~km}$ distance from the edge of the Thorndon basin to the waterfront in the 2D models (see Figure 2). It is also of interest to examine trends in the model response for various distances from the basin edge. Figure 8 shows the horizontal spectral amplification relative to the POTS record at the eight locations across the Thorndon basin indicated in Figure 2 for all considered ground motions for Cases B2 and F2. These mesh cases are selected as they had the best overall correspondence to observations in previous analyses and can therefore be used to gauge the broader ability of the 2D models to represent basin effects as well as to directly compare the relative response from these two cases, which as previously discussed, differ only in their treatment of the velocity contrast across the Wellington Fault zone. 


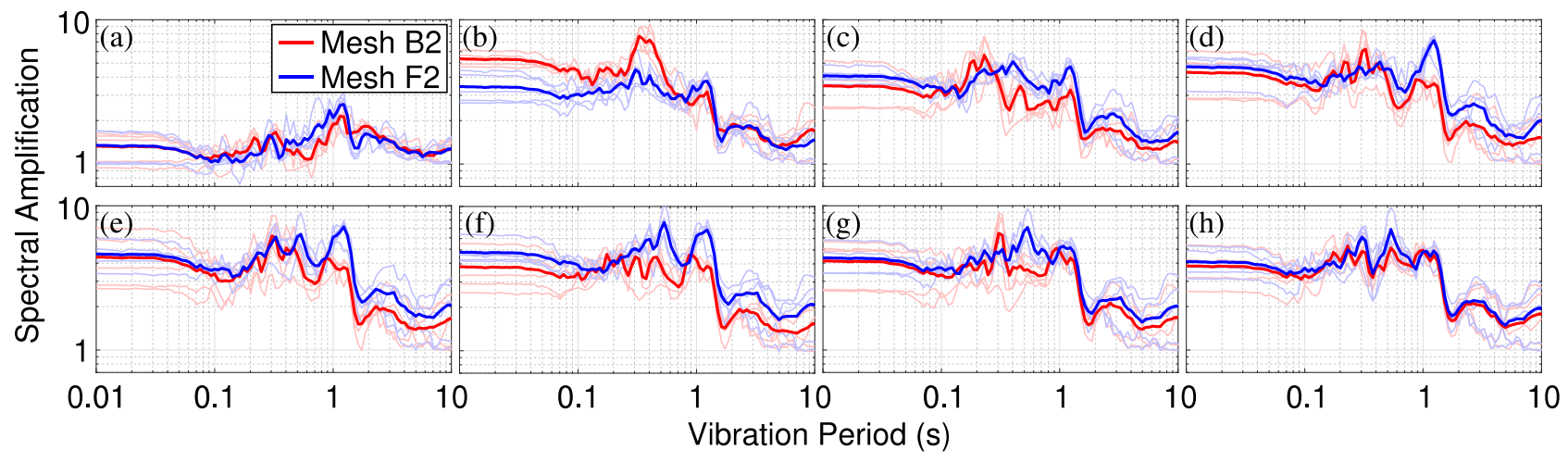

Figure 8: Spectral amplification relative to POTS for $2 D$ model Cases $B 2$ and F2 at series of locations along the Thorndon basin. Successive subfigures show results at increasing distance from basin edge. Subfigure (a) shows amplification close to basin edge and subfigure (h) at seawall as indicated in Figure 2.

As shown in Figure 8, there are clear differences between the two model responses, though there are some general trends shared by each. Both cases have relatively low amplifications near the basin edge which then tend to increase over particular period ranges moving away from the edge before becoming somewhat stable nearer to the seawall. The primary differences between Cases B2 and F2 are related to the distance from the basin edge to the locations with significant amplification and the period range associated with these increased amplifications. The nature of these features is consistent with the basin-edge effect described by Kawase [7] who used numerical models to demonstrate the development of a relatively narrow band of increased amplification due to constructive interference of vertically propagating $\mathrm{SH}$-waves with diffracted Rayleigh waves generated at the basin edge. Kawase [7] found that position of this band is dependent on the depth of the basin and the frequency content of the ground motion, with deeper basins moving the band away from the basin edge, and motions with higher predominant frequencies moving it closer to the edge. Graves et al. [8] also examined the development of similar effects in the Santa Monica area, where the basin structure near the edge is strikingly similar to the Thorndon basin, with secondary faults splaying off of a main fault leading to deeper lateral velocity contrasts as is considered in Case F2.

The development of basin-edge effects is evident in the results of Figure 8, with a band of increased amplification in the 1-2 second range further from the basin edge exhibited by Case F2 and shown in Figures 8(d)-(f), which is about 540-730 $\mathrm{m}$ from the basin edge, and a narrower band of increased amplification around 0.3-0.5 seconds for Case B2 shown in Figure 8(b), which is about $135 \mathrm{~m}$ from the basin edge. It is not clear which model response is more consistent with the actual basin response, but given that the treatment of the Wellington Fault zone is the only difference between these two models, it is clear that the inclusion of the velocity contrast across the fault zone significantly changes the basin-edge effects in the 2D models by creating a deeper lateral impedance contrast beneath the soil basin. Based on these results, it is important that consideration for this potential velocity contrast be made in future ground motion modelling of Wellington.

\section{EFFECTS OF RANDOM SOIL SHEAR WAVE VELOCITY ON MODEL RESPONSE}

To more fully explore the potential of 2D models for ground response and to provide more evidence of the limitations of SH1D site response analysis for basin sites, a subset of models are developed to consider random variations in soil shear wave velocity. Unlike the models discussed in all previous sections, which consider the depth-dependent shear wave velocity profile described by Equations 1 and 2 and shown in Figure 3(a), this additional subset of models considers random perturbations to the depth-dependent shear wave velocity profile using random field theory as previously discussed in the Model Development section of this paper.

Twenty random field models are developed and analysed in the current study, with ten comprising different realisations with anisotropic variations in shear wave velocity where the vertical autocorrelation length is one tenth of that in the horizontal direction, and ten realisations with isotropic variations where the vertical and horizontal autocorrelation lengths are the same. All models use the rock velocity structure of Case F2 from Table 1, which includes a horizontal velocity contrast across the Wellington Fault zone. These twenty models are analysed using Ground Motion A from Table 2 and the results are summarised via the horizontal acceleration response spectra and spectral amplifications at the reference site shown in Figures 9 and 10 for the anisotropic and isotropic models, respectively. For comparison, Figures 9 and 10 include the corresponding SH1D and baseline depth-dependent shear wave velocity results for Case F2 (previously shown in Figure 5), and the results of each individual realisation are shown in addition to the average response across all realisations.

Figures 9 and 10 highlight the effects of soil variability on the response at the reference site, particularly in regard to the spectral amplification relative to the POTS site. This variability tends to be greater at lower periods, and there is a pronounced decrease in variability for periods greater than 2 seconds likely due to the reduced effect of the considered variations on longer wavelengths. Anisotropic variation in shear wave velocity is more realistic in the context of most soil deposition processes, and though the particular correlation lengths used in these analyses are not based on any direct data, the anisotropic cases appear to be superior to the isotropic cases based on the results of Figures 9 and 10. The isotropic results are influenced by single outlier case in one realisation with nearly continuous horizontal zones of higher shear wave velocities throughout the stiff soil layer, essentially creating a large horizontal impedance boundary not reflected in any of the other random field realisations. While this outlier tends to skew the overall isotropic results, which potentially biases the comparison to the anisotropic cases, the isotropic treatment of soil variability has a greater tendency to develop such outliers.

For the anisotropic cases, an examination of the individual amplification ratios shown in Figure 9(b) indicates that several of the random velocity cases match the observed amplification significantly better than the average over certain period ranges, however, none of the ten anisotropic cases match the observations perfectly across all periods. This suggests that more realisations are likely necessary to get a comprehensive assessment of the site and basin response, however, the results 

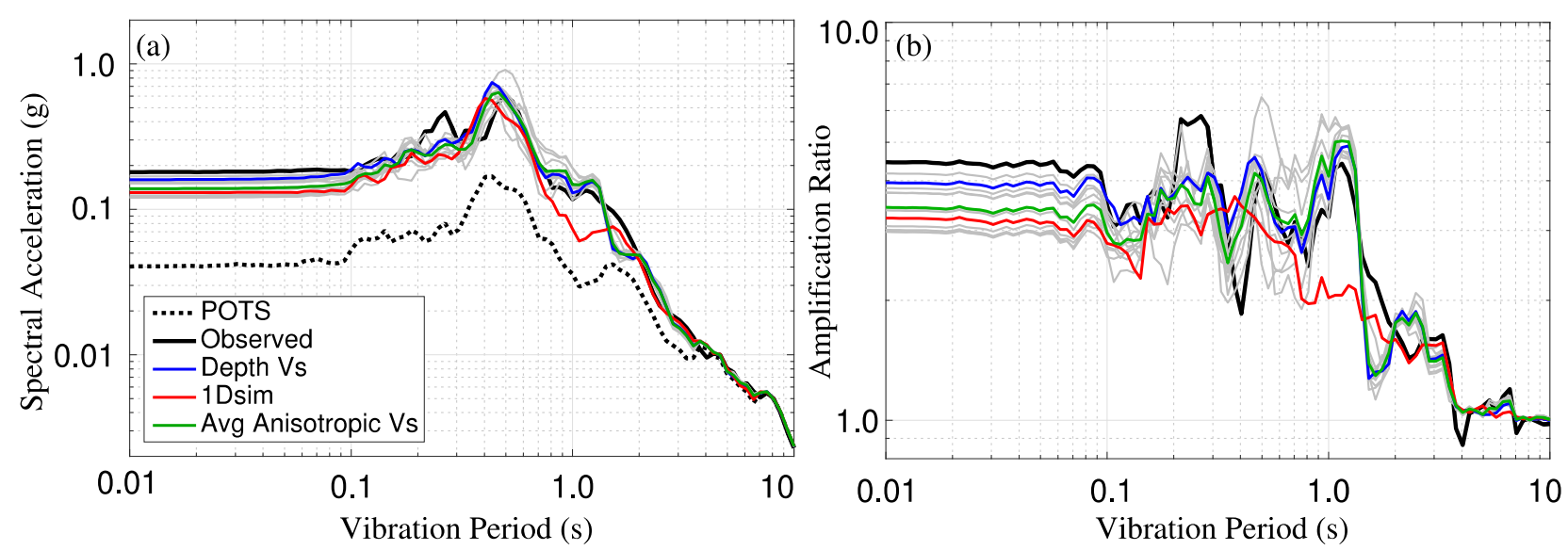

Figure 9: Surficial response at reference site for Ground Motion A considering 2D models with anisotropic random field models of soil shear wave velocity. Grey lines represent individual random field realisations and green line is mean of all realisations. Blue line represents base depth-dependent soil shear wave velocity model. (a) Acceleration response spectra; (b) Amplification relative to POTS rock motion.
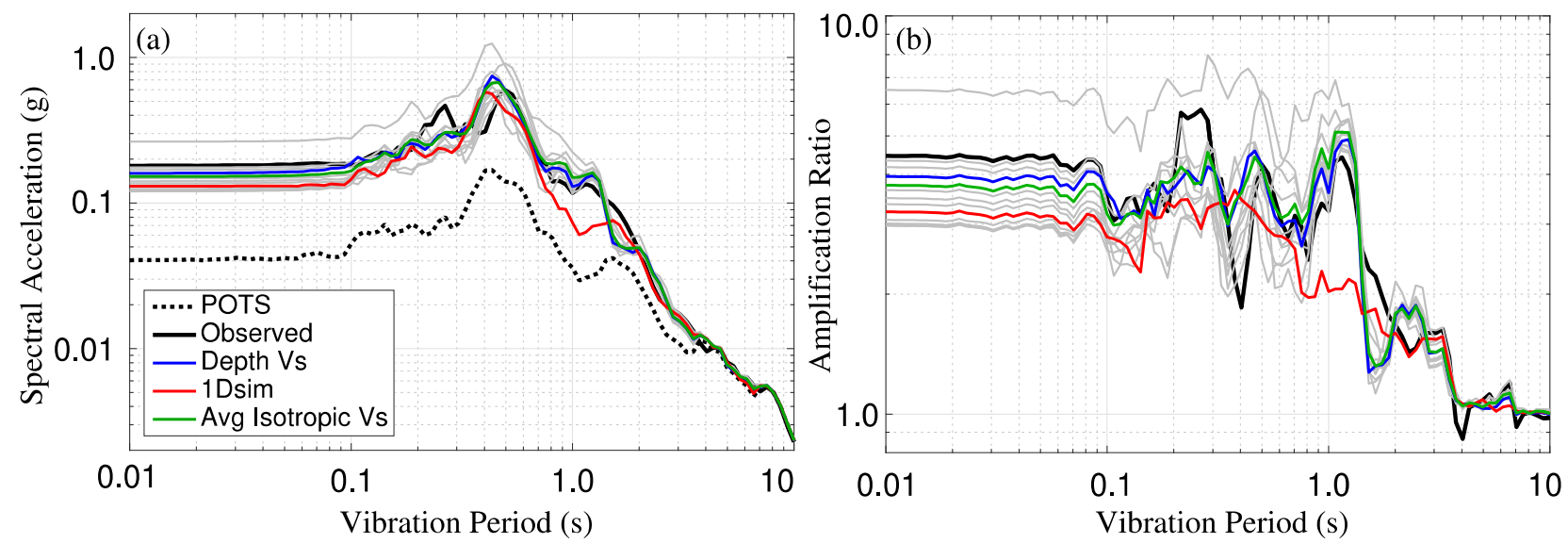

Figure 10: Surficial response at reference site for Ground Motion A considering $2 D$ models with isotropic random field models of soil shear wave velocity. Grey lines represent individual random field realisations and green line is mean of all realisations.

Blue line represents base depth-dependent soil shear wave velocity model.

(a) Acceleration response spectra; (b) Amplification relative to POTS rock motion.

from the ten anisotropic cases here would likely be sufficient for design purposes as they tend to envelope the observed response at the reference site. Rather than analysing more realisations with the same random field model parameters, it would arguably be better to consider more realisations with different sets of horizontal autocorrelation lengths, anisotropy factors, and standard deviations, as recent work by de la Torre et al. [28] has demonstrated the sensitivity of the surficial site amplification to these parameters and such an approach would provide a broader consideration of material variability. It may also be appropriate to consider further analyses based on different baseline shear wave velocity profiles, as there is a fair amount of uncertainty in these initial values in addition to uncertainty in how they vary spatially.

The results of Figures 9 and 10 again highlight the shortcomings of SH1D site response analysis for representing the response of basin sites or other sites with complex conditions. Not only do the previously made observations related to the inability to represent the observed response at all period ranges still apply, the variability in material conditions enabled through the application of random field theory in the $2 \mathrm{D}$ models cannot be considered in conventional SH1D analysis in a corresponding manner. Variability can be considered by analysing a series of randomised soil profiles, however, this does not capture the full spectrum of effects, particularly in regard to wave scattering, that occur in 2D or 3D analysis with random fields. The hybrid
2D-1D site response analysis approach of de la Torre et al. [28] is a promising alternative to standard SH1D analysis that can capture wave scattering and other effects related to a $2 \mathrm{D}$ random velocity field, but this approach is not typically used and the vast majority of site response analyses performed in practice and research applications suffer from the limitations of the SH1D assumptions. For sites that are well-characterised using 1D wave propagation, this is not an issue, but for sites near basin edges or where other 2D and 3D features dominate the site response, the use of SH1D analysis can lead to site response predictions that poorly match observations across a range of periods as demonstrated in this paper.

\section{CONCLUSIONS}

2D plane strain and SH1D numerical ground response models were developed and analysed to examine the factors influencing site response and basin effects at a reference site and at multiple locations across the Thorndon basin of Wellington. These models considered linear viscoelastic constitutive response to emphasise wave propagation effects rather than near-surface soil nonlinearity. Several shear wave velocity structures for the rock layers underlying the soil basin were considered, and some of the 2D models used random field theory models to account for variability in the shear wave velocity within the soil basin and demonstrate how this effects the simulated response. 
The results of this study demonstrated some of the limitations of using conventional SH1D site response analysis for sites located in a complex region dominated by basin effects. Where 2D models were able to reasonably approximate observed response spectra and spectral amplification at the reference site, corresponding SH1D models did not match the observed response across a range of periods, and in particular were deficient for periods of 1-2 seconds where basin effects are evident in both the observed and 2D model response. The advantages of $2 \mathrm{D}$ ground response simulation were also demonstrated in regard to the ability to capture small and large scale material variability within the region.

2D model results at the reference site and across the Thorndon basin demonstrated that the development of basin edge effects in the numerical models manifested as zones of increased spectral amplification over different ranges of vibration periods. These simulated basin edge effects compared reasonably well to observations made across several ground motions at the reference strong motion station site, and were present across the basin in accordance with expectations based on previous work $[7,8]$. Further ground motion modelling is required in order to fully evaluate the extent, character, and consequences of these basin edge effects for different seismic sources in the region, however, it is clear from the current study that the potential for a velocity/stiffness contrast across the Wellington Fault caused by secondary faulting on the hanging wall side warrants further consideration as it plays a key role in the development of basin edge effects in the models.

It is also evident that better and more comprehensive characterisation of soil and rock shear wave velocity (and other properties) is necessary within the Wellington region in order to maximise the utility of numerical simulations and better understand previous empirical observations. For example, it should be noted that the 2D model domain passes through the Aotea Fault [29], though the effects of this fault on the basin geometry are not considered in the current study. The Semmens et al. [9] basin model that informs the 2D models developed here did not make consideration for the portion of the Aotea Fault that impacts the model domain, and the recentlypublished update of the Semmens et al. model by Kaiser et al. [30] was not published at the time that the $2 \mathrm{D}$ model development was undertaken for this study. Based on the Kaiser et al. [30] basin model, it is clear that consideration of the Aotea Fault would create a steep-sided basin boundary on the eastern side of the model domain similar to the boundary created by the Wellington Fault, and it is likely that this altered basin geometry would impact the results from the 2D models, particularly in regard to basin-edge generated surface waves and other basin edge effects.

Despite this need for further research, the current study has demonstrated the improved capability of 2D ground response models for sites in the Thorndon basin relative to $1 \mathrm{D}$ analysis. Even though the current 2D models are ultimately still rough approximations of the true complexity of the basin conditions e.g., based on the geometry of the basement rock it is likely that 3D basin edge effects are important, and near-surface soil nonlinearity in larger magnitude events cannot be captured in linear elastic analysis - the improved response prediction across a range of periods relative to $1 \mathrm{D}$ analysis is clear.

\section{ACKNOWLEDGMENTS}

Elevation and bathymetry data were sourced from the LINZ Data Service (https://data.linz.govt.nz) and licensed by the Wellington Regional Council for re-use under the Creative Commons Attribution 4.0 International license. Seismograms were obtained from the New Zealand Strong Motion Database [31]. The random fields were generated using the GeoStat-
Framework/GSTools [32] under the GNU General Public License v3. This work was partially supported by the New Zealand Earthquake Commission and QuakeCoRE, a New Zealand Tertiary Education Commission-funded Centre. This is QuakeCoRE publication number 0468.

\section{REFERENCES}

1 Thompson EM, Baise LG, Tanaka Y and Kayen RE (2012). "A taxonomy of site response complexity". Soil Dynamics and Earthquake Engineering, 41: 32-43. https://doi.org/10.1016/j.soildyn.2012.04.005

2 Kaklamanos J and Bradley BA (2018). "Challenges in predicting seismic response with 1D analyses: Conclusions from $114 \mathrm{KiK}-$ net vertical seismometer arrays". Bulletin of the Seismological Society of America, 108(5A): 2816-2838. https://doi.org/10.1785/0120180062

3 Pilz M and Cotton F (2019). "Does the 1D assumption hold for site response analysis? A study of seismic site responses and implications for ground motion assessment using KiKnet strong-motion data". Earthquake Spectra, 35(2): 883905. https://doi.org/10.1193/050718EQS113M

4 Afshari K and Stewart JP (2019). "Insights from California vertical arrays on the effectiveness of ground response analysis with alternative damping models". Bulletin of the Seismological Society of America, 109(4): 1250-1264. https:/doi.org/10.1785/0120180292

5 Bard PY and Bouchon M (1980a). "Seismic response of sediment filled valleys part 1: the case of incident $\mathrm{SH}$ waves". Bulletin of the Seismological Society of America, 70(4): 1263-1286. https://pubs.geoscienceworld.org/ssa/bssa/articlepdf/70/4/1263/2703450/BSSA0700041263.pdf

6 Bard PY and Bouchon M (1980b). "Seismic response of sediment filled valleys part 2: the case of incident P and SV waves". Bulletin of the Seismological Society of America, 70(5): 1921-1941.

https://pubs.geoscienceworld.org/ssa/bssa/articlepdf/70/5/1921/2703850/BSSA0700051921.pdf

7 Kawase H (1996). "The cause of the damage belt in Kobe: "The basin-edge effect," constructive interference of the direct S-wave with basin-induced diffracted/Rayleigh waves". Seismological Research Letters, 67(5): 25-34. https:/doi.org/10.1785/gssrl.67.5.25

8 Graves RW, Pitarka A and Somerville PG (1998). "Groundmotion amplification in the Santa Monica area: effects of shallow basin-edge structure". Bulletin of the Seismological Society of America, 88(5): 1224-1242. https://pubs.geoscienceworld.org/ssa/bssa/articlepdf/88/5/1224/2709443/BSSA0880051224.pdf

9 Semmens S, Perrin ND and Dellow GD (2010). "It's Our Fault-Geological and Geotechnical Characterisation of the Wellington Central Business District". GNS Science Consultancy Report 2010/176, GNS, Lower Hutt, New Zealand, 52pp.

https://www.gns.cri.nz/content/download/7997/43532/file/ Semmens\%20et\%20al_GNS\%20CR\%202010-176.pdf

10 Holden C, Kaiser A, Van Dissen R and Jury R (2013). "Sources, ground motion and structural response characteristics in Wellington of the 2013 Cook Strait earthquakes". Bulletin of the New Zealand Society for Earthquake Engineering, 46(4): 188-195. https://doi.org/10.5459/bnzsee.46.4.188-195

11 Bradley BA, Wotherspoon LM and Kaiser AE (2017). "Ground motion and site effect observations in the Wellington region from the $\mathrm{M}_{\mathrm{w}} 7.8$ Kaikoura, New Zealand earthquake". Bulletin of the New Zealand Society for 
Earthquake Engineering, 50(2): 94-105. https://doi.org/10.5459/bnzsee.50.2.94-105

12 Bradley BA, Wotherspoon LM, Kaiser AE, Cox BR and Jeong, S (2018). "Influence of site effects on observed ground motions in the Wellington region from the $\mathrm{M}_{\mathrm{w}} 7.8$ Kaikōura, New Zealand earthquake". Bulletin of the Seismological Society of America, 108(3B): 1722-1735. https://doi.org/10.1785/0120170286

13 Benites R and Olsen KB (2005). "Modeling strong ground motion in the Wellington metropolitan area, New Zealand". Bulletin of the Seismological Society of America, 95(6): 2180-2196. https://doi.org/10.1785/1020040223

14 Adams BM, Davis R, Berrill J and Taber J (1999). "TwoDimensional Site Effects in Wellington and the Hutt Valley - Similarities to Kobe. " University of Canterbury Research Report No. 99-3, Department of Civil Engineering, University of Canterbury. https://www.eqc.govt.nz/sites/public_files/208-Twodimensional-site-effects-Wn-HuttValley-Kobe.pdf

15 Adams BM, Osborne NM and Taber JJ (2003). "The basinedge effect from weak ground motions across the faultbounded edge of the Lower Hutt Valley, New Zealand". Bulletin of the Seismological Society of America, 93(6): 2703-2716. https://doi.org/10.1785/0120010277

16 Lensen GJ (1958) "The Wellington Fault from Cook Strait to Manawatu Gorge". New Zealand Journal of Geology and Geophysics, 1(1): 178-196. https://doi.org/10.1080/00288306.1958.10422803

17 Van Dissen RJ and Berryman KR (1996). "Surface rupture earthquakes over the last 1000 years in the Wellington region, New Zealand, and implications for ground shaking hazard". Journal of Geophysical Research, 101(B3): 59996019. https://doi.org/10.1029/95JB02391

18 Litchfield NJ, Van Dissen R, Sutherland R, Barnes PM, Cox SC, Norris R, Beavan RJ, Langridge R, Villamor P, Berryman K, Stirling M, Nicol A, Nodder S, Larmarche G, Barrell DJA, Pettinga JR, Little T, Pondard N, Mountjoy J and Clark K (2013). "A Model of Active Faulting in New Zealand: Fault Zone Parameter Descriptions". GNS Science Report 2012/19, GNS, Lower Hutt, New Zealand, 120 pp. https://www.gns.cri.nz/static/pubs/2012/SR\% 202012-019.pdf

19 GNS Science (2009). New Research Shows Lower Threat from Wellington Fault. www.gns.cri.nz/Home/News-andEvents/Media-Releases/Lower-threat-from-Wellingtonfault (accessed December 2018).

20 Langridge R, Van Dissen RJ, Rhoades D, Villamor P, Little T, Litchfield N, Clark K and Clark D (2011). "Five thousand years of surface rupture on the Wellington Fault, New Zealand: implications for recurrence and fault segmentation". Bulletin of the Seismological Society of America, 101(5): 2088-2107. https://doi.org/10.1785/0120100340
21 McKenna F (2011). "OpenSees: a framework for earthquake engineering simulation". Computing in Science and Engineering, 13(4): 58-66. https://doi.org/10.1109/MCSE.2011.66

22 McGann CR, Arduino P and Mackenzie-Helnwein, P (2012). "Stabilized single-point 4-node quadrilateral element for dynamic analysis of fluid saturated porous media”. Acta Geotechnica, 7(4): 297-311. https://doi.org/10.1007/s11440-012-0168-5

23 Cox BR and Vantassel J (2018). Dynamic Site Characterization of Wellington, New Zealand. DesignSafeCI [publisher], dataset. https://doi.org/10.17603/DS24M6J

24 New Zealand Geotechnical Database (NZGD) (2018). www.nzgd.org.nz (accessed July 2018).

25 Heße F, Prykhodko V, Schülter S and Attinger S (2014). "Generating random fields with a truncated power-law variogram: A comparison of several numerical methods". Environmental Modeling and Software, 55: 32-48. https://doi.org/10.1016/j.envsoft.2014.01.013

26 Tenzer R, Sirguey P, Rattenbury M and Nicolson J (2010). "A digital rock density map of New Zealand". Computers and Geosciences, 37(8): 1181-1191. https://doi.org/10.1016/j.cageo.2010.07.010

27 Joyner WB and Chen ATF (1975). "Calculation of nonlinear ground response in earthquakes". Bulletin of the Seismological Society of America, 65(5): 1315-1336. https://pubs.geoscienceworld.org/ssa/bssa/articlepdf/65/5/1315/2699824/BSSA0650051315.pdf

28 de la Torre CA, Bradley BA and McGann CR (2020). "2D geotechnical site response analysis including soil heterogeneity and wave scattering". Earthquake Spectra, under review, submitted August 2020.

29 Barnes PM, Nodder SD, Woelz S and Orpin AR (2019). "The structure and seismic potential of the Aotea and Evans Bay faults, Wellington, New Zealand". New Zealand Journal of Geology and Geophysics, 62(1): 46-71. https://doi.org/10.1080/00288306.2018.1520265

30 Kaiser AE, Hill MP, Wotherspoon L, Bourguignon S, Bruce ZR, Morgenstern R and Giallini S (2019). "Updated $3 D$ Basin Model and NZS 1170.5 Subsoil Class and Site Period Maps for the Wellington CBD: Project 2017-GNS03-NHRP”. GNS Science Consultancy Report 2019/01, GNS, Lower Hutt, New Zealand, 63 pp. https://www.gns.cri.nz/static/download/NHRP/NHRPKaikoura-Kaiser.pdf

31 Van Houtte C, Bannister S, Holden C, Bourguignon S and McVerry G (2017). "The New Zealand Strong Motion Database". Bulletin of the New Zealand Society for Earthquake Engineering, 50(1): 1-20. https://doi.org/10.5459/bnzsee.50.1.1-20

32 Müller S and Schüler L (2019). GeoStat-Framework/ GSTools: Bouncy Blue (Version v1.0.1). Zenodo. https://doi.org/10.5281/zenodo.2543658 